\title{
Corrosion in the Flue Gas Cleaning System of a Biomass-Fired Power Plant
}

\author{
Montgomery, Melanie; Olesen, R. E.; Gensmann, P.
}

Published in:

Journal of Failure Analysis and Prevention

Link to article, DOI:

10.1007/s11668-017-0238-y

Publication date:

2017

Document Version

Peer reviewed version

Link back to DTU Orbit

Citation $(A P A)$ :

Montgomery, M., Olesen, R. E., \& Gensmann, P. (2017). Corrosion in the Flue Gas Cleaning System of a Biomass-Fired Power Plant. Journal of Failure Analysis and Prevention, 17(2), 195-204.

https://doi.org/10.1007/s11668-017-0238-y

\section{General rights}

Copyright and moral rights for the publications made accessible in the public portal are retained by the authors and/or other copyright owners and it is a condition of accessing publications that users recognise and abide by the legal requirements associated with these rights.

- Users may download and print one copy of any publication from the public portal for the purpose of private study or research.

- You may not further distribute the material or use it for any profit-making activity or commercial gain

- You may freely distribute the URL identifying the publication in the public portal

If you believe that this document breaches copyright please contact us providing details, and we will remove access to the work immediately and investigate your claim. 


\title{
Corrosion in the flue gas cleaning system of a biomass fired power plant
}

\author{
M. Montgomery ${ }^{1 *}$, R.E. Olesen ${ }^{2}$ and P. Gensmann ${ }^{3}$, \\ ${ }^{1}$ DTU Mekanik, Produktionstorvet, 2800 Lyngby, Denmark \\ ${ }^{2}$ COWI A/S Parallelvej 2, 2800 Lyngby, Denmark \\ ${ }^{3}$ HOFOR-Amagerværket, Kraftværksvej 37, 2300 København
}

\begin{abstract}
After only a few years operation of a biomass power plant, corrosion damage was observed in the flue gas cleaning system (FGCS). The corrosion was on the lower part of the gas/gas heat exchanger (GGH) fabricated from A242 weathering steel, where UNS S31600 bolts were used to attach sealing strips to the rotor. Thick iron oxides (up to $5 \mathrm{~mm}$ ) had formed on the weathering steel and these oxides also contained chlorine and sulphur. In this area of the heat exchanger, weathering steel has not had the optimal wet/dry cycles required to achieve a protective oxide. Due to the thick growing oxide on the rotor, the UNS S31600 bolts were under stress and this together with the presence of accumulated chlorine between the sealing strips and bolts resulted in stress corrosion cracking and rupture.

In addition $\mathrm{Zn}-\mathrm{K}-\mathrm{Cl}$ deposits were agglomerated in the duct after the DeNOx unit. $\mathrm{Zn}$ was also a constituent of corrosion products in various places in the ducts resulting in hygroscopic compounds. The presence of $\mathrm{Zn}$ in these cases was not from the fuel, and is assumed to have originated from $\mathrm{Zn}$ containing primer (used to protect the plant during construction) reacting with flue gas constituents containing chlorine $(\mathrm{KCl}$ and $\mathrm{HCl})$.
\end{abstract}

\section{Introduction}

Amager unit 1 was first operational in 1971 as a coal-fired plant. It was extensively renovated to a $350 \mathrm{MW}$ thermal multi-fuel suspension-fired plant which has been in operation since 2009. The initial intention was to use both coal and biomass; however since commissioning only biomass has been used in the boiler.

The flue gas flow through the flue gas cleaning system (FGCS) is shown in Figure 1. The flue gas is led through the flue gas desulphurisation unit (FGD) where the majority of sulphur and chlorine species are removed. After that it is led through the gas/gas heat exchanger (GGH) which is a rotating regenerative heat exchanger on a counter flow principle. The GGH has inlet flue gas (approx. $50^{\circ} \mathrm{C}$ ) from the FGD and the flue gas is heated to approx. $300^{\circ} \mathrm{C}$ so that removal of NOx gases can occur in the denitrification unit (DeNOx). This "clean" gas returns to the GGH where the outlet temperature is $80-90^{\circ} \mathrm{C}$. It takes only a few minutes for the GGH to make a full rotation, and the temperature of the lower part of the GGH cycles from approx. $50^{\circ} \mathrm{C}$ to $80-90^{\circ} \mathrm{C}$. It is in this area that the majority of corrosion was observed.

The GGH rotor is fabricated in A242 weathering steel (CORTEN) and the heat transfer elements are carbon steel of specifications EN10088, where the heat transfer elements in the lower $1 / 3$ of the GGH are carbon steel (EN10209) protected by an enamel coating. Adjustable

*Corresponding author mmon@mek.dtu.dk 
sealing strips on the rotor are used to minimize leakage of the untreated to the treated gas. These sealing strips are fabricated in UNS N10276 (Hastelloy C276) and are bolted to the weathering steel rotor frame using UNS SS0316 (AISI 316) bolts. The gas from the outlet is approx. $85^{\circ} \mathrm{C}$ and is led via the booster fan to the stack. The flue gas ducts after the GGH were carbon steel, and were in some cases protected with a $\mathrm{Zn}$ rich epoxy primer.

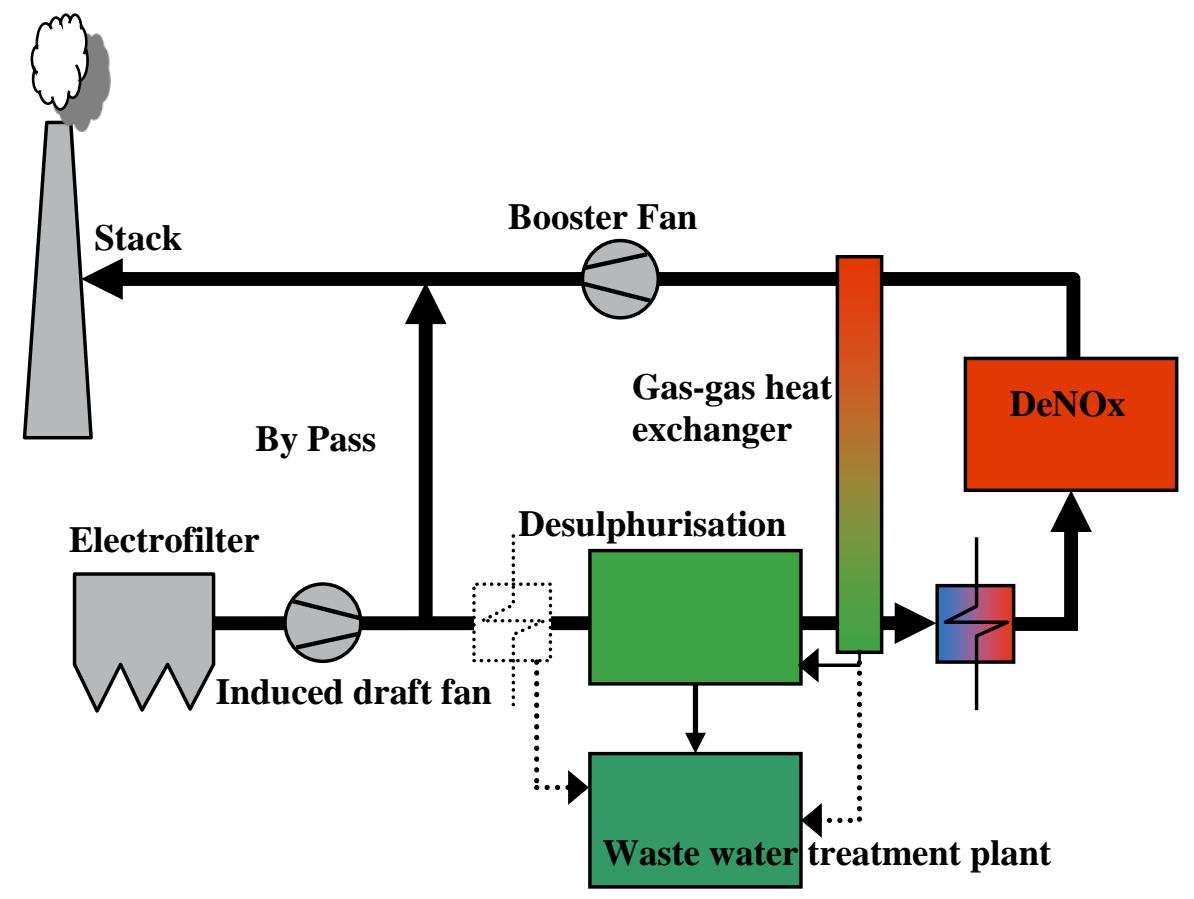

Figure 1: Schematic drawing of flue gas cleaning unit.

After 15000 hours of operation, significant corrosion damage was observed in the lower part of the GGH closest to the centre of the rotor (Figure 2). Here there was up to $2 \mathrm{~mm}$ metal loss and many of the UNS S31600 bolts had failed leading to the unfortunate consequence that radial sealing strips had been found further on down the system in the duct before the booster fan. There were also large amounts of spalled rust in the ducts after the GGH which had originated from the GGH rotor. In addition there were deposit agglomerates of unknown composition or origin. In some cases there was the appearance of "wet" corrosion products when the FGCS was inspected during downtime.

Literature reveals that tail end corrosion in biomass boilers has been previously observed in Sweden [1,2], Denmark [3] and Germany [4] and has been related to the $\mathrm{HCl}$ content in the flue gas. This paper describes and explains the observations of corrosion in the FGCS which were linked to the firing of biomass.

\section{Deposits/Corrosion products in the GGH}

During annual inspections, corroded components and corrosion product/deposit samples were collected from the GGH and booster fan area. These were analyzed utilizing light optical microscopy (LOM), scanning electron microscopy with electron diffraction spectrometry (SEMEDS) and x-ray diffractometry (XRD). The SEM-EDS equipment used cannot accurately measure elemental concentrations below $\mathrm{Na}$ in the periodic table thus measurements of oxy- 
gen content should be considered as indicative of its presence allowing a certain margin for inaccuracy. Table 1 lists material specifications of the components discussed in this paper.

Table 1: Specifications of materials used in the gas-gas heat exchanger (wt. \%)

\begin{tabular}{|l|l|l|l|l|l|l|l|l|l|l|}
\hline & & $\mathrm{C}$ & $\mathrm{Fe}$ & $\mathrm{Si}$ & $\mathrm{Mn}$ & $\mathrm{Cr}$ & $\mathrm{Mo}$ & $\mathrm{Cu}$ & $\mathrm{Ni}$ & $\mathrm{W}$ \\
\hline Rotor & $\mathrm{A} 242$ & 0.12 & $\mathrm{Rest}$ & $0.25-0.75$ & $0.20-0.50$ & $0.50-1.25$ & & $\begin{array}{l}0.25- \\
0.55\end{array}$ & 0.65 & \\
\hline $\begin{array}{l}\text { Radial } \\
\text { seals }\end{array}$ & UNS N10276 & $<0.01$ & $<3$ & $<0.08$ & $<0.5$ & 23 & 16 & 1.6 & rest & $\begin{array}{l}3.0- \\
4.5\end{array}$ \\
\hline Bolts & UNS SS31600 & $<0.08$ & Rest & & & $16-18$ & $2-3$ & & $10-14$ & \\
\hline
\end{tabular}

Figure 2 shows the lower part of the gas-gas heat exchanger where severe corrosion was observed. Oxide had formed on the frame of the rotor fabricated in weathering steel. Some UNS SS31600 bolt heads had ruptured (as shown by the arrows) which had resulted in detachment of the UNS N10276 sealing strips.

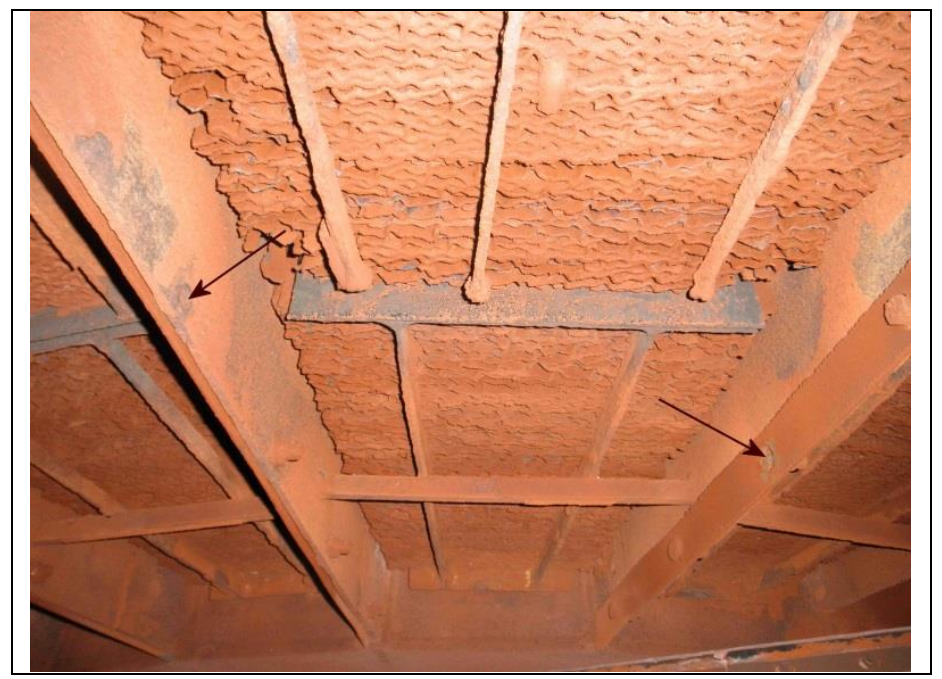

Figure 2: Photo of lower part of gas-gas heat exchanger where arrows indicate missing bolts.

\subsection{Deposit from top of $G G H$}

Fine white powder was observed at the top of the GGH and in the DeNOx unit. If more straw had been fired in the time period preceding inspection, then more "white powder" was observed. These particles have the morphology and composition as shown in Figure 3, and with $\mathrm{XRD}$, the phases $\mathrm{KCl}$ (sylvite JCPDS 41-1476), $\mathrm{K}_{2} \mathrm{SO}_{4}$ (arcanite JCPDS 70-1488) and $\mathrm{K}_{3} \mathrm{Na}\left(\mathrm{SO}_{4}\right)_{2}$ (JCPDS 74-0398) have been identified. Neither ammonium chloride nor ammonium bisulphate was detected. Wet analysis was undertaken to investigate the presence of ammonia compounds as described in [4] but only trace amounts were detected. Similar sized submicron particles were also present in other areas after the FGD and were also present in the crevice between the sealing strips and weathering steel rotor. The micrograph to the right reveals submicron particles. 


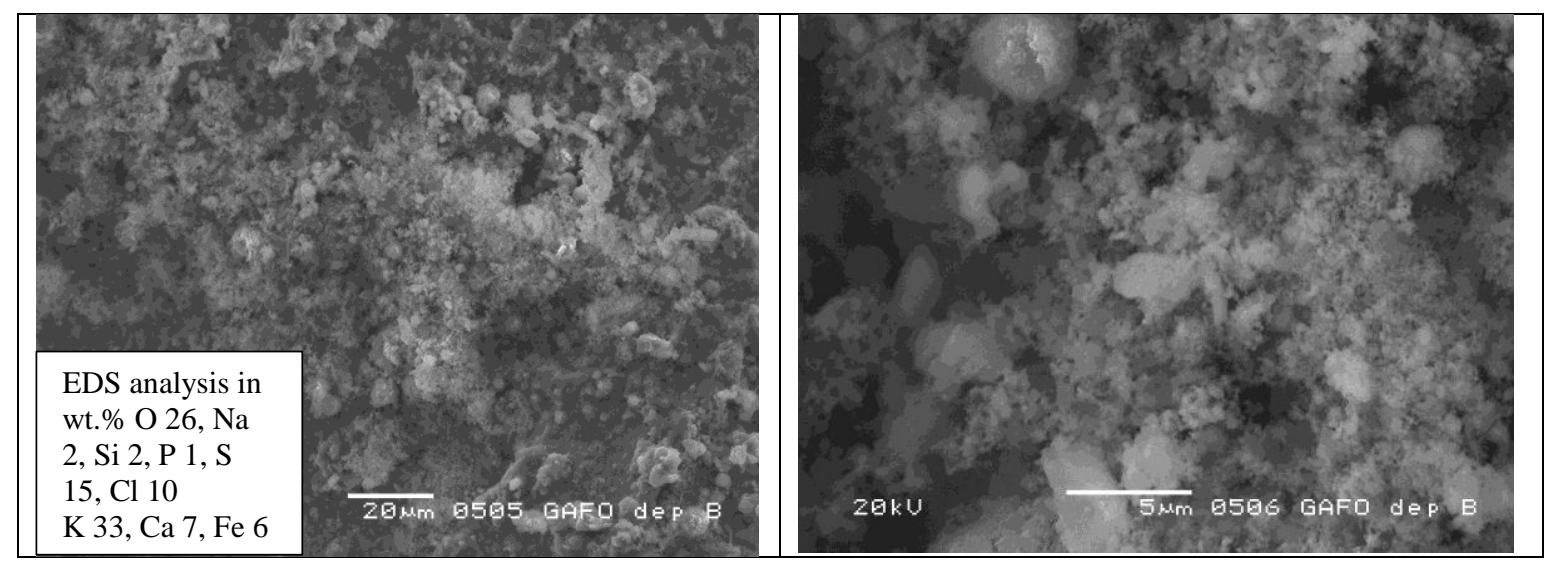

Figure 3: SEM-EDS analysis of fine particles typically found in GGH and DeNOx unit.

\subsection{Oxide removed from $\mathrm{GGH}$ rotor frame}

The oxide thickness on the weathering steel was up to $5 \mathrm{~mm}$ after two years exposure and consisted of many layers of oxide and not a single protective oxide as is expected for a weathering steel to yield good protection. A cross-section of the deposit removed from the inner part of the rotor is shown in Figure 4, where the lower brown layer was furthest away from the steel surface and closest to the flue gas. Different areas across the oxide were investigated with SEM-EDS.

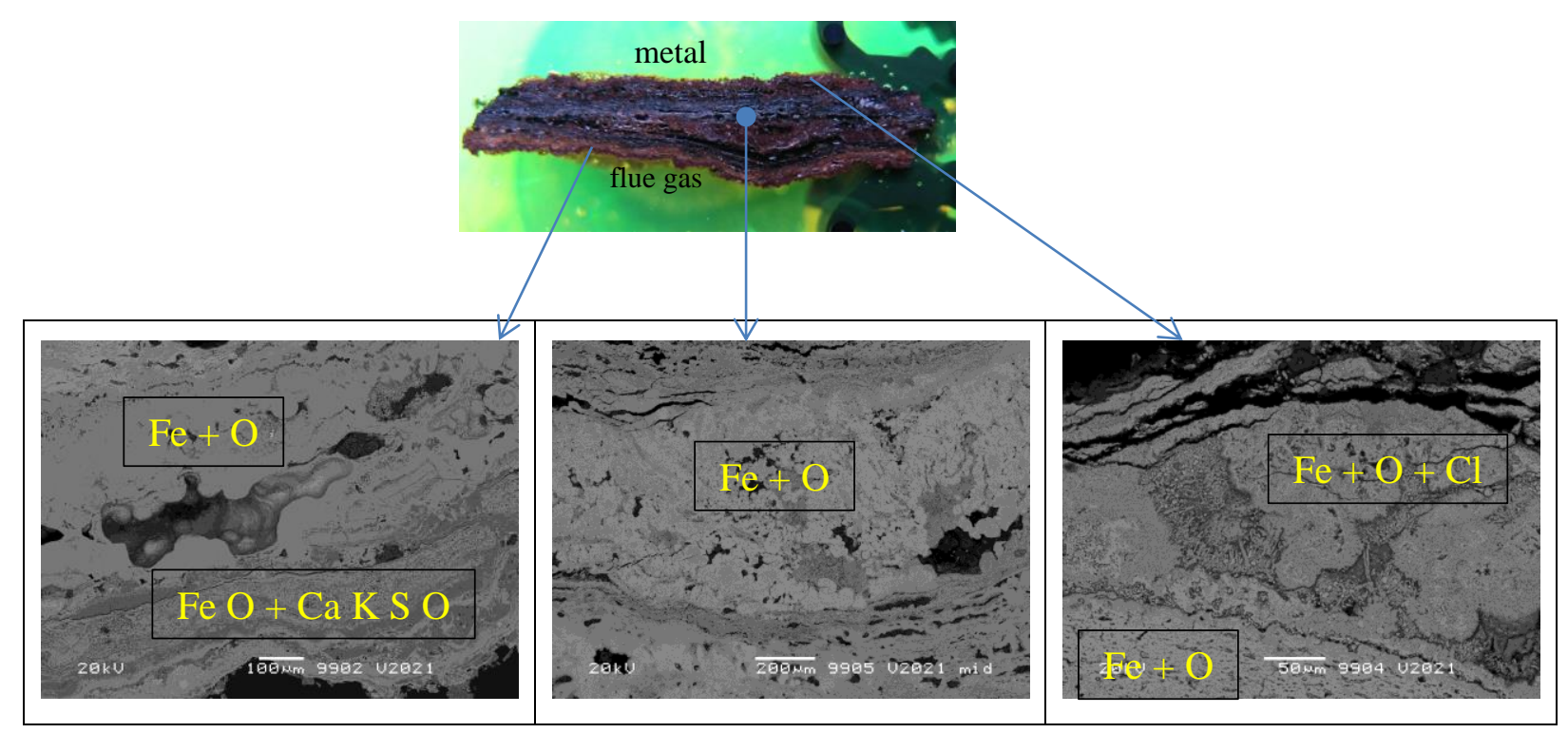

Figure 4: Cross-section of corrosion product from the GGH rotor.

On the flue gas side (LHS micrograph), there was a high content of calcium, potassium and sulphur together with iron and oxygen indicating iron oxide together with calcium sulphate and potassium sulphate. Chlorine was not present. The middle of the oxide layer (middle micrograph) contained iron and oxygen, and the oxide closest to the steel surface (RHS micrograph) was predominantly iron and oxygen however there was a higher concentration of chlorine. Thickness of oxide layers was variable depending on location; for example, the oxide removed from the centre of the GGH rotor was twice the thickness of the oxide closer to the outer circumference. SEM-EDS analyses elemental composition (but not the elements below oxygen) so this technique was supplemented with x-ray diffraction to give more information about the phases present. The specimens were ground to obtain a fine powder, thus it is the 
whole of the specimen that is analysed and not a particular surface. Phases which constitute under 3 vol. $\%$ of the total sample will be below the detection limit. Based on both SEM-EDS and XRD, the following phases were detected: akageneite $\beta$ - $\mathrm{FeOOHCl}$, goethite $\alpha \mathrm{FeOOH}$ and maghemite $\mathrm{Fe}_{2} \mathrm{O}_{3}$. In addition the presence of amorphous phases which cannot be determined with XRD were revealed from the diffractrogram.

\subsection{UNS S31600 bolts}

One of the ruptured bolts was examined on the fractured surface with SEM-EDS and revealing an equiaxed dimple structure. Particles containing $\mathrm{K}, \mathrm{Cl}, \mathrm{S}$, and $\mathrm{O}$ were also present in these areas Figure 5a. The bolt was also cut longitudinally and examined with LOM and SEM-EDS (Figure 5b and c). There were many cracks in the bolt and analysis at the bottom of the thread revealed high content of chlorine, some sulphur, but only traces of potassium and calcium.

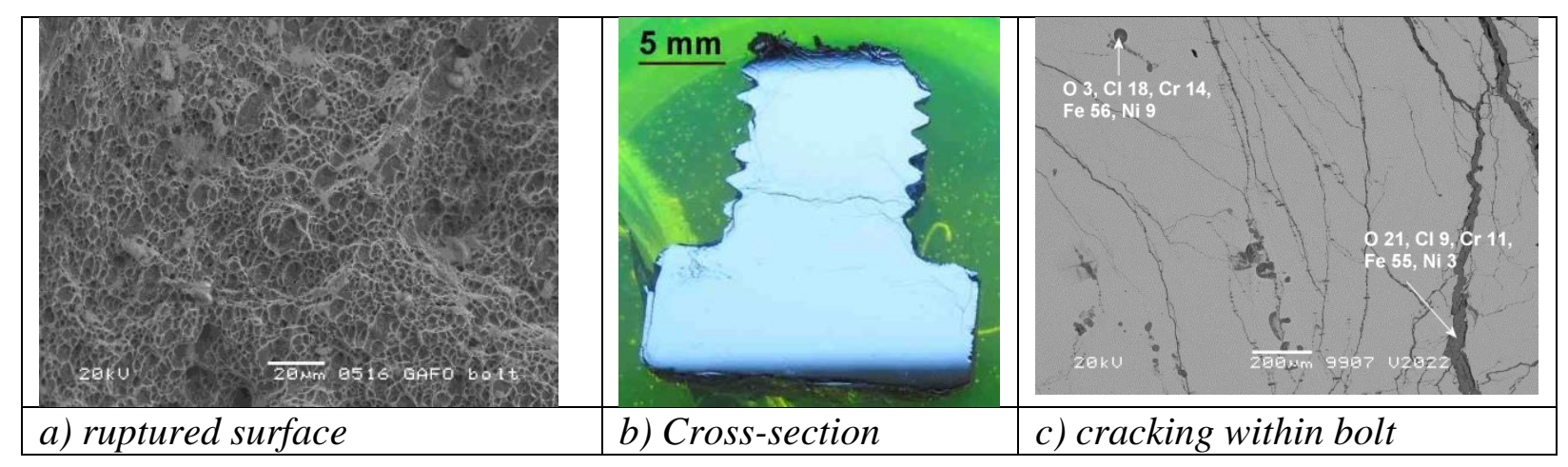

Figure 5: Failed stainless steel bolts revealing widespread cracking. Analysis in wt. \%.

The corrosive species detected within the bolt were predominantly chlorine and oxygen together with the constituents of the stainless steel. In addition traces of sulphur could be detected. As can be seen from the crack morphology, there is transcrystalline attack and chlorine was detected within the cracks. A bolt was also removed from the middle part of the GGH weathering steel rotor where there was less visible corrosion. The corrosion attack that was most prevalent for the bolts was pitting corrosion approx. $50 \mu \mathrm{m}$ deep (Figure 6).
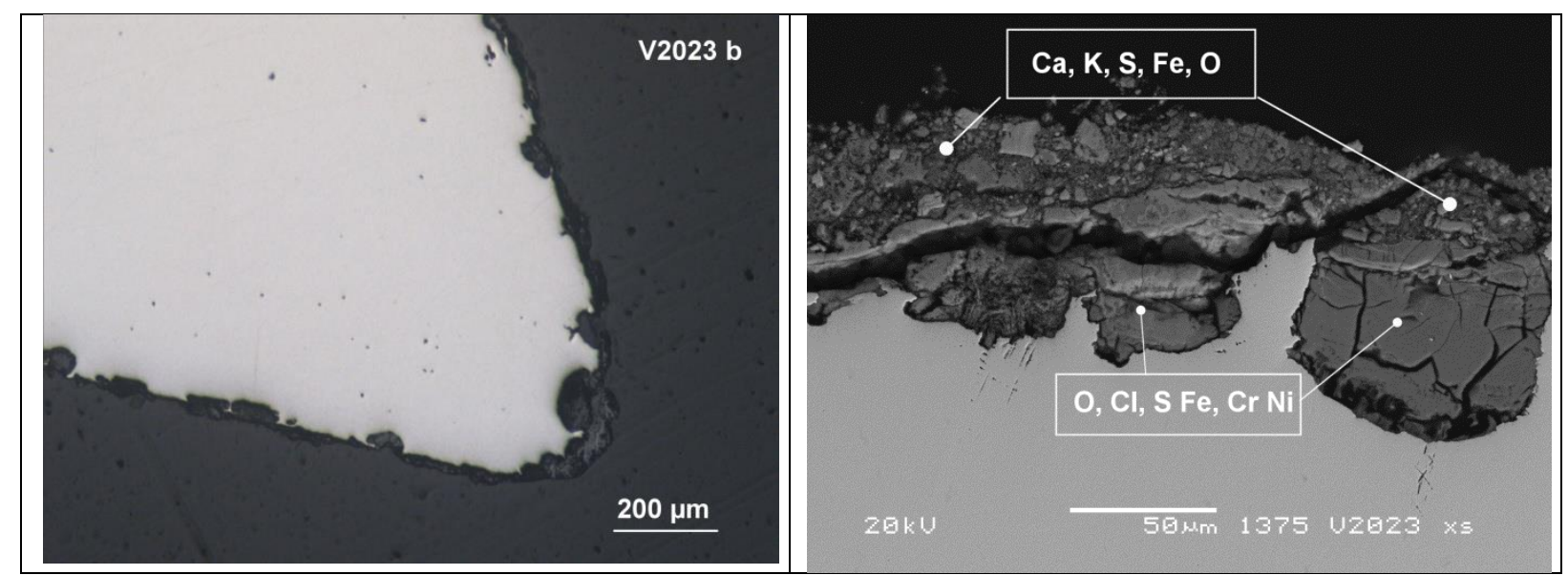

Figure 6: Analysis of a bolt (not ruptured) from the middle of the GGH. Analysis in wt. \%

There were occasional cracks present however not to the extent that the bolt would risk rupture. The chemical composition of the corrosion products within the pits revealed by SEM- 
EDS was potassium and calcium on the outer side closest to the flue gas and chlorine and sulphur within the corrosion product closest to the metal.

\subsection{UNS N10276}

One of the detached sealing strips recovered from the duct after the GGH was examined, especially on the position it was bolted to weathering steel. Visually, there was no evidence of corrosion. A cross section of the strip revealed neither cracks nor pits. UNS N10276 contains approx. $60 \mathrm{wt} . \%$ nickel and there was no nickel in the corrosion products, but both the sulphur and chlorine were present within the deposit adjacent the alloy.

\section{Corrosion in the area of the booster fan duct.}

\subsection{Agglomerate formation}

A large amount of spalled oxide was observed immediately before the booster fan which had the same composition and appearance of that found in the GGH. The fact that deposits/oxides accumulated in this area could be due to a 90 degree bend in the duct before the booster fan, but also due to the presence of the booster fan in the duct as a physical hindrance to large airborne particles. The transportation of these spalled oxides from the GGH also result in erosion of the booster fans blades. In addition large deposit agglomerates were found here in the initial years of service. One of these agglomerates is shown in Figure 7a and it was clear that these deposits were difficult to prepare for analysis as they were very hygroscopic (Fig. 7b). Analysis of these deposits with SEM-EDS in Figure 7c revealed the presence of $\mathrm{Zn}, \mathrm{Cl}$ and $\mathrm{K}$.

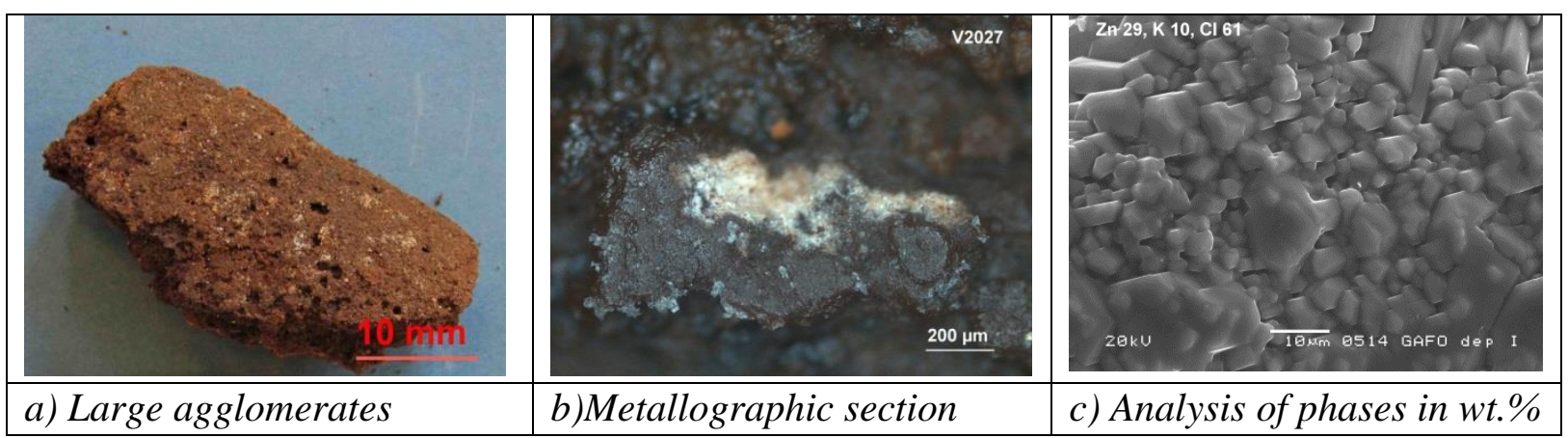

Figure 7: Analysis of large agglomerates found in the duct after the GGH.

b) Localised pitting attack

During inspections in 2013 and 2014, in some areas the protective primer was still visible, and in other areas this coating had been removed by corrosion/erosion. Figure 8 compares two different locations in the FGCS after the GGH showing the red colour of the primer and what is observed at the interface. Figure 8 (left) shows two areas of the duct adjacent to one another where primer was and was not used. Some pitting attack of the primer is observed exposing the underlying material. Figure 8 (right) from the silencer shows the interface between coating and non coating, where a black fluid was seeping out. 


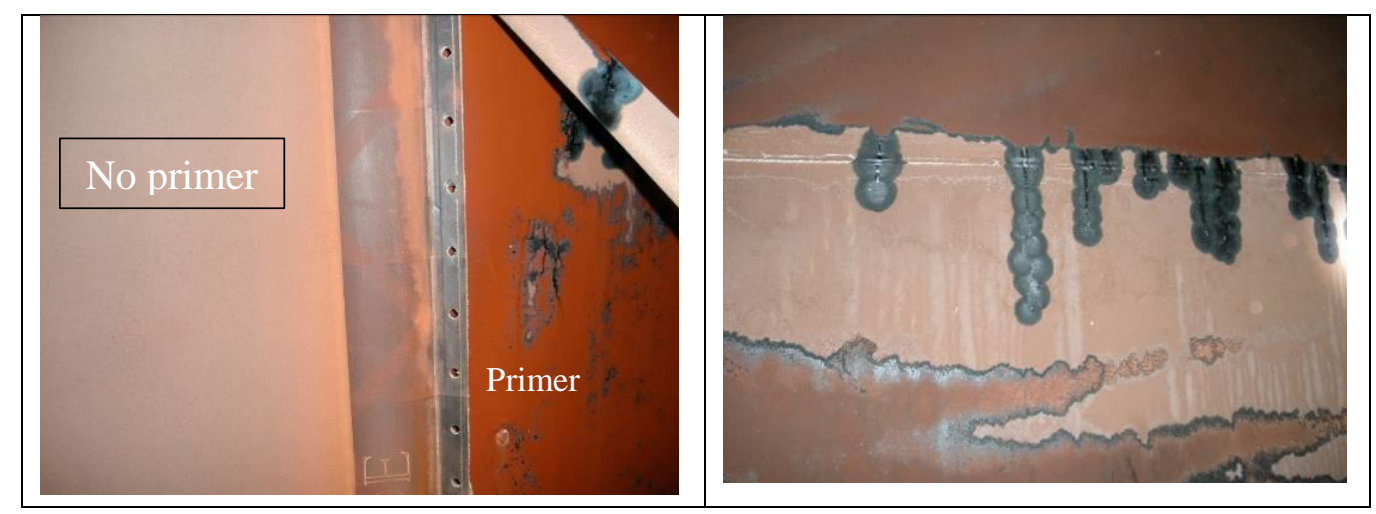

Figure 8: Duct before booster fan (left) and duct before silencer (right).

Figure 9 shows such a location where liquid was apparent, and this was collected with a pipette, and measured with universal indicator paper to have a $\mathrm{pH}$ of 3.5-4.5. The main components as measured with ion chromatography were $407 \mathrm{~g} / \mathrm{L} \mathrm{Cl}^{-}$and $4.8 \mathrm{~g} / \mathrm{L} \mathrm{SO}_{4}{ }^{2-}$ and using $\mathrm{ICP}, 235 \mathrm{~g} / \mathrm{L} \mathrm{Zn}$, and $1.6 \mathrm{~g} / \mathrm{L} \mathrm{Mg}$ was measured. Other elements/compounds were measured to $\mathrm{mg} / \mathrm{l}$ level, e.g. ammonium $0.16 \mathrm{mg} / \mathrm{l}$ (measured with Fagerberg testkit). Since the presence of ammonium chloride was suspected based on [4], different samples collected after the GGH were analysed with wet chemistry methods and XRD, however ammonium was only present at very low levels. A portion of the fluid was allowed to crystallise on filter paper and this crystallised product was analysed with SEM-EDS (Figure 9 right) to contain $\mathrm{Zn}, \mathrm{Cl}, \mathrm{K}$ and $\mathrm{Fe}$ together with oxygen probably indicating a mixture of $\mathrm{ZnCl}-\mathrm{KCl}$ and $\mathrm{Fe}-\mathrm{O}-\mathrm{Cl}$.

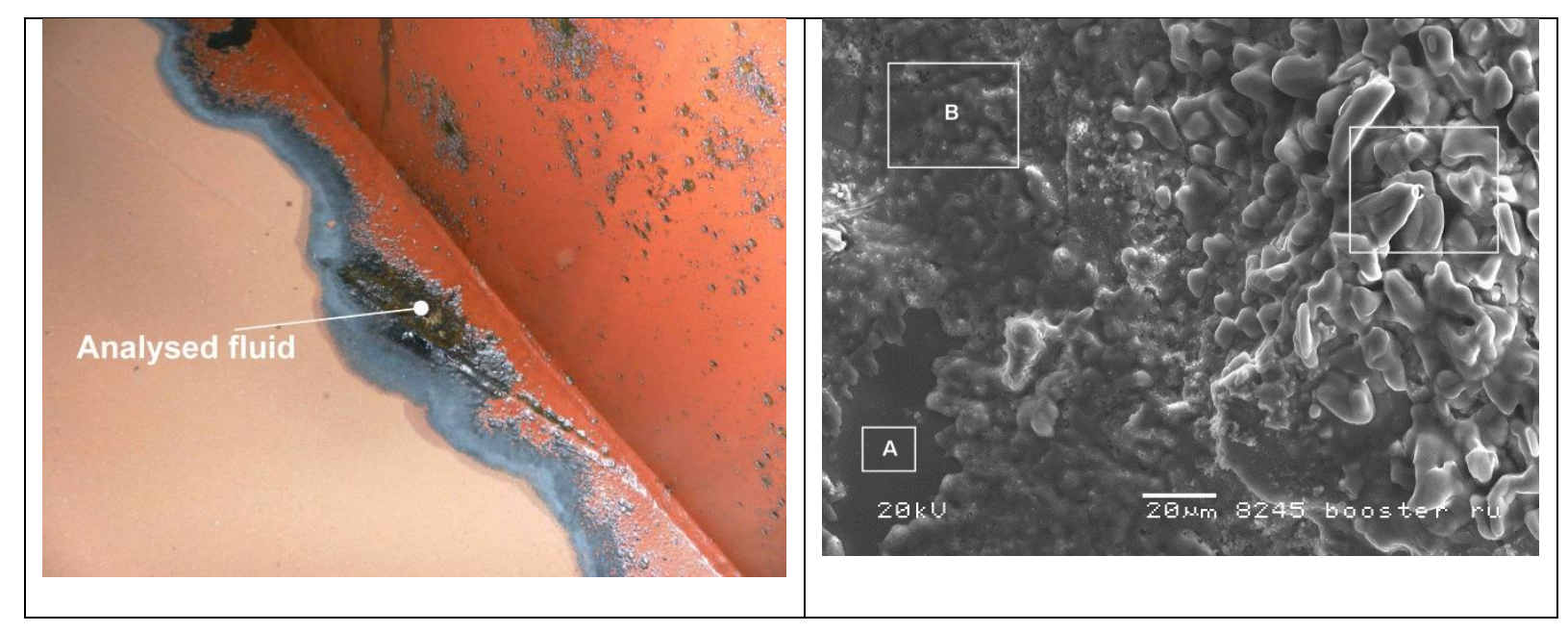

\begin{tabular}{|l|l|l|l|l|l|}
\hline & O & Cl & K & Fe & Zn \\
\hline A & 31 & 34 & 11 & 9 & 16 \\
\hline B & 14 & 43 & 16 & 8 & 20 \\
\hline C & & 54 & 18 & 2 & 27 \\
\hline
\end{tabular}

Figure 9: SEM-EDS analysis of liquid from booster duct where Zn primer had been used.

\section{Discussion}

As a consequence of corrosion in the FGCS after only two years operation, various corrosion products and deposits were analysed, and on-line corrosion monitoring was installed. An example of the on-line monitoring is shown in Figure 10 where the sensor thickness decreases 
(right hand y-axis) when temperature changes as the FGCS is started up and shutdown. By correlating operation data with on-line sensor thickness just after the GGH, it was clear that corrosion was linked to start-up and shutdowns. The first arrow indicates shutdown and therefore downtime corrosion and the second arrow is plant start-up which also gives rise to corrosion. The corrosion during start-up was observed to decrease when firing only with wood pellets compared with straw pellets. Further detailed results are given in references 5 and 6.

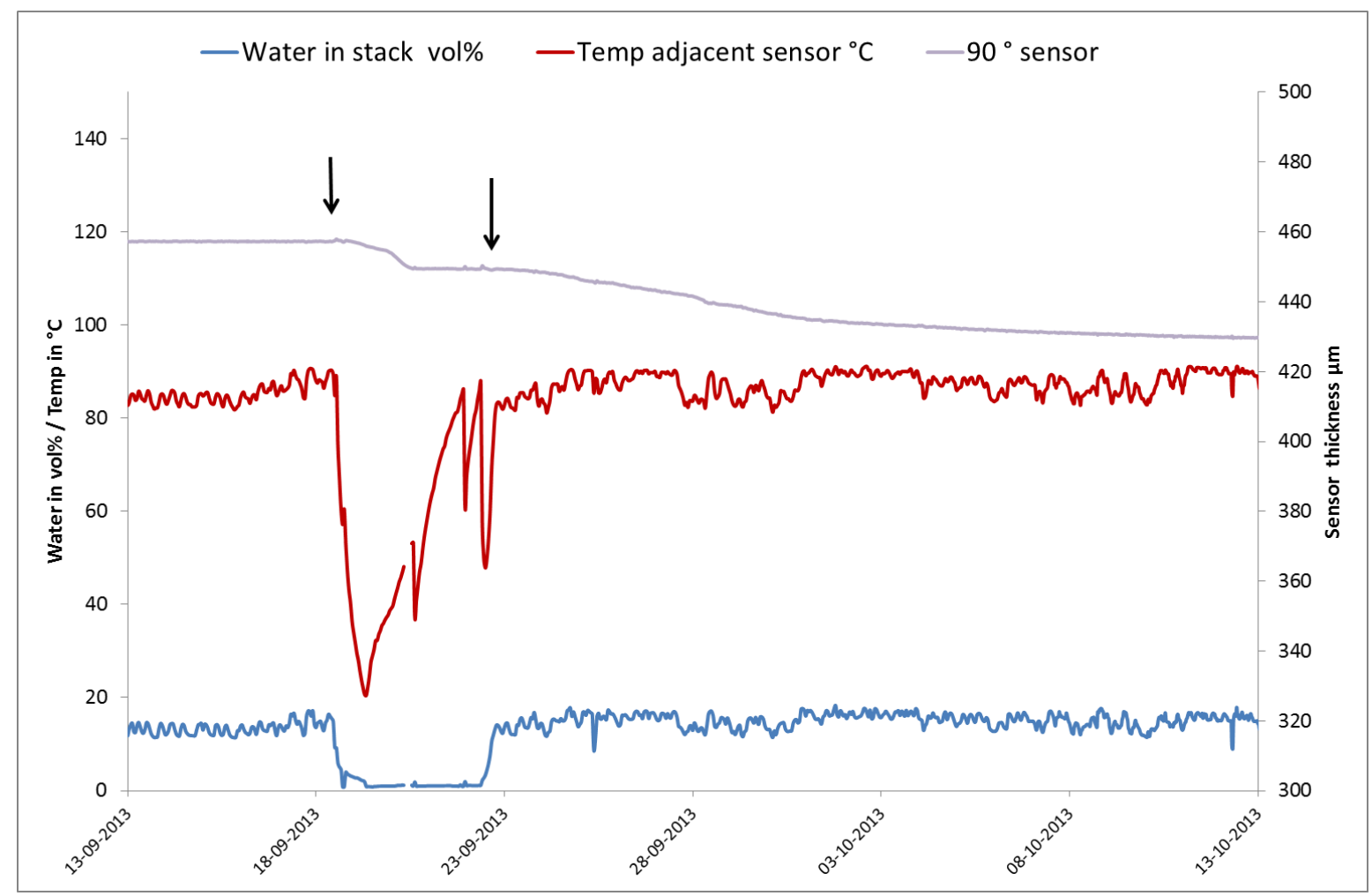

Figure 10: Correlation of reduction in sensor thickness and operation parameters temperature and water content.

From the analysis of corrosion products/deposits, the same components which result in corrosion in the boiler, i.e. calcium, potassium, chlorine and sulphur are also present as particles in the flue gas in the FGCS and can contribute to corrosion together with the $\mathrm{HCl}$ content in the gas. From 2009-2013, a mixture of straw and wood pellets were used in the plant and high corrosion rates were observed. Therefore passing the flue gas through the FGD did not adequately remove $\mathrm{Cl}$ species from the flue gas.

\subsection{Corrosion of weathering steel rotor and its consequences}

The fast corrosion rates of the weathering steel rotor especially at the inner part of the rotor can also be explained by temperature fluctuations around the dewpoint of water and $\mathrm{HCl}$ since the lower part of the GGH is continually cycling between $50^{\circ} \mathrm{C}-85^{\circ} \mathrm{C}$. Weathering steels contain small amounts of alloying elements such as copper, chromium, nickel, phosphorous and manganese to produce a more protective oxide layer compared to carbon steel. The optimal protective layer is formed in the wet-dry cycle. Initially an oxide layer is formed in wet conditions and under dry conditions the layer becomes less porous and more compact, and thus provides the additional protection against corrosion. In the wet cycle lepidocrocite $\gamma$-FeOOH 
forms, which is converted to goethite $\alpha-\mathrm{FeOOH}$ on drying [7]. Thus there is an inner protective layer of goethite and an outer layer of lepidocrocite and the corrosion rate has parabolic or logarithmic kinetics. In comparison, carbon steel does not consist of two layers but a disordered mixture of these two constituents. Small amounts of alloying elements such as $\mathrm{Cu}$ and $\mathrm{Cr}$ contribute to maintain a nano-amorphous protective layer on the metal surface, thus preventing diffusion of corrosive species to the metal surface. Weathering steel has performed well in industrial environments where there is high $\mathrm{SO}_{2}[8]$ and CORTEN A has been found to yield sufficient corrosion resistance in the gas preheater in oil-fired power plants where there is high sulphur content [9]. It is reported that copper in weathering steels forms copper hydroxy sulphates in $\mathrm{SO}_{2}$ environments, and these compounds precipitate in pores of the rust layer and thus hinder ingress of corrosive species[8]. When the required wet/dry cycles are not present, high corrosion rates were measured, and maghemitite $\gamma-\mathrm{Fe}_{2} \mathrm{O}_{3}$ or akaganeite $\beta$ $\mathrm{FeOOHCl}$ forms if $\mathrm{Cl}$ is present [10]. Such layers are not adherent to the steel surface and will easily exfoliate, so if the optimal conditions are not present, the weathering steel will behave like carbon steel.

For the rust specimens removed from the GGH, SEM-EDS studies reveal that chlorine is a main constituent in the oxide especially close to the metal surface. XRD revealed that goethite, akageneite and maghemite were formed. This indicates that some of the desired goethite is formed; however the presence of akageneite and maghemite indicates that the wet-dry cycle did not facilitate formation of a protective layer, and that chlorine also contributes to the formation of a non protective layer. Chlorine is concentrated in corrosion products at the corrosion front and therefore must diffuse through the oxide, again indicating that the oxide is nonprotective. In contrast, sulphur was found primarily on the outer side of the corrosion product and probably condenses onto the surface oxide during shutdown. The lower part of the GGH where the temperature is continually fluctuating every few minutes around the dewpoint of water and $\mathrm{HCl}$ will corrode the most compared to areas higher in the GGH and in the booster duct which have a more constant temperature. CFD calculations indicated localised areas of high humidity in the GAFO which corresponded to the areas of high corrosion. Thus local differences in temperature and humidity result in higher corrosion rates of the GGH where thick non-protective oxide flakes were formed which were transported further down the plant and resulted in erosion problems of the booster fan.

The UNS N10276 sealing strips suffered almost no corrosion in this environment; however their detachment occurs because UNS SS31600 bolts rupture. These bolts revealed transgranular cracking in locations where there were high corrosion rates of the weathering steel rotor and chlorine was present within the cracks. In areas where there was less corrosion of the weathering steel, the bolts exhibited pitting corrosion. Due to the thick oxide formed on the weathering steel in these areas, the bolts are subjected to increasing tensile stress during exposure as $2 \mathrm{~mm}$ of steel is replace by an oxide layer with a 2-3 times greater volume on either side in a period of 2 years. The presence of chlorine via the flue gas and the tensile stress results in rupture as stainless steels have a high sensitivity to stress corrosion cracking. Figure 11 is a schematic showing how the bolt is subjected to tensile stress on both sides as shown by arrows, resulting in fracture. 
A242 Weathering steel

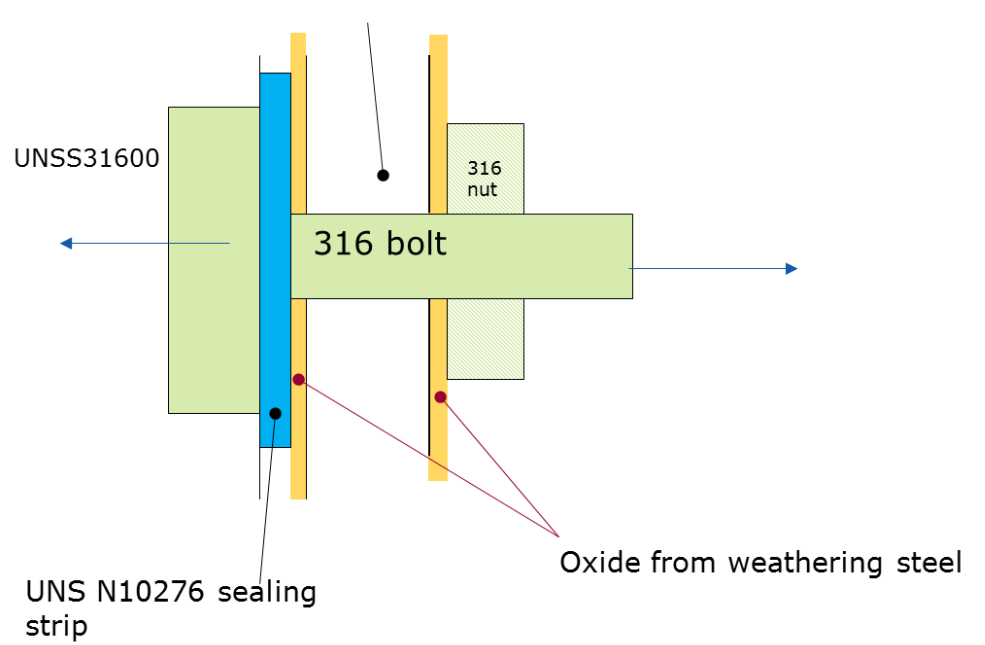

Figure 11: Schematic diagram showing how tensile stresses can occur for the AISI 316 bolt.

Stress corrosion cracking tests at $43^{\circ} \mathrm{C}, 85^{\circ} \mathrm{C}$ and $120^{\circ} \mathrm{C}$ for AISI 304 and 316 steel revealed that failure occurred at $43^{\circ} \mathrm{C}$ and not at $85^{\circ} \mathrm{C}$ or $120^{\circ} \mathrm{C}[11]$. As expected AISI 304 was more susceptible to SCC than AISI 316 steel. Another study on SCC of AISI 304 steel revealed that SCC occurred to a greater extent at $45^{\circ} \mathrm{C}$ and $60^{\circ} \mathrm{C}$ compared to $30^{\circ} \mathrm{C}$. From these results the temperature range of $43-60^{\circ} \mathrm{C}$ is most critical and this is within the temperature range of the lower part of the GGH. In addition a relative humidity of $60 \%$ results in a higher susceptibility to cracking at $45^{\circ} \mathrm{C}$ and $60^{\circ} \mathrm{C}$ compared to $100 \%$ [12]. Thus relative humidity was also a contributory factor where a semi moist environment is more critical than if the component was fully immersed. Yang et al [13] measured the corrosion current of both carbon steel and 316 stainless steel at $50^{\circ} \mathrm{C}$ under $\mathrm{KCl}$ salt with increasing humidity. It was found that by increasing the humidity, the corrosion rate increased uniformly for the carbon steel (i.e. relevant for CORTEN) however for the 316 steel, the corrosion current increased drastically at $70 \%$ relative humidity. In both cases the corrosion current increased with increase in relatively humidity to $95 \%$. Thus where there was less corrosion of the weathering steel, the bolts were attacked by pitting corrosion and therefore there would be a longer time to failure. In these areas, the humidity was probably lower perhaps due to a decrease in humidity and entrained water droplets. These bolts were replaced with UNS N10276 bolts in the vulnerable locations resulting in no further failure of bolts. Later, the plant was rebuilt so the FGD could be bypassed when only biomass was used as a fuel. Thus during operation, the temperature of the lower part of the GAFO was higher than $50-80^{\circ} \mathrm{C}$ and therefore above the dewpoint of $\mathrm{HCl}$ and water. This reduced corrosion of the weathering steel rotor immensely.

\subsection{Use of Zn primer in the FGCS}

Analysis of deposits found in the duct after the DeNOx in the first few years reveals the presence of very hygroscopic $\mathrm{Zn}-\mathrm{K}-\mathrm{Cl}$ agglomerates. The fuel used in AMV1 is wood and straw pellets, and not demolition wood. From deposit analysis from the boiler, no $\mathrm{Zn}$ was found, and it was not present in the GGH. It is suggested that the presence of $\mathrm{Zn}-\mathrm{K}-\mathrm{Cl}$ agglomerates indicate that a reaction has occurred in the DeNOx between $\mathrm{KCl}$ particles from the flue gas and $\mathrm{Zn}$ containing primer used to protect the DeNOx components during construction. At 280-305 ${ }^{\circ} \mathrm{C}$ which is the working temperature in the DeNOx unit, $\mathrm{KCl}$ particles could react with $\mathrm{Zn}$ to form $\mathrm{K}-\mathrm{Zn}-\mathrm{Cl}$ volatile components, see Figure 12 . These have probably been en- 
trained in the flue gas and would agglomerate together at lower temperatures. Once the $\mathrm{Zn}$ coating has been removed from the DeNOx unit, this reaction will no longer occur, therefore these agglomerates were not observed in later years.

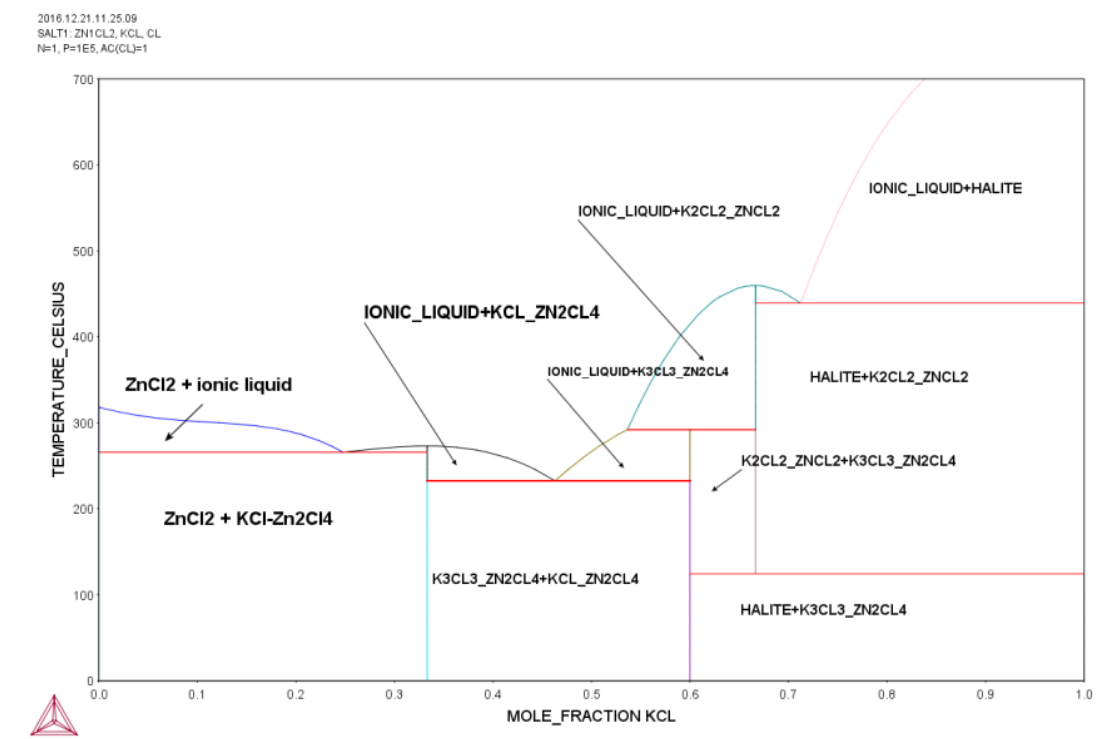

Figure 12: Eutectic molten salts of $\mathrm{KCl}-\mathrm{ZnCl}_{2}[14]$.

There was a difference in appearance between components with a primer coating and those without. Those without a primer coating exhibited general corrosion. For structures coated with a primer, in some places it was observed that there was no primer as this had been removed due to corrosion and erosion. At the interface between the original primer surface and the steel surface, a black compound was present, which was hygroscopic during shutdown, had an acidic $\mathrm{pH}$ and was rich in $\mathrm{Zn}$ and $\mathrm{Cl}$. $\mathrm{ZnCl}_{2}$ products are more hygroscopic than iron chlorides or $\mathrm{KCl}$ [3]. Especially during shutdown as the temperature decreases below the dewpoint, pitting corrosion can occur where hygroscopic deposits are present, because of the localised high concentrations of chlorine and low $\mathrm{pH}$. It is not known whether the coatings result in reducing or increasing corrosion rates, however they can give an appearance of increased attack. The primer probably reduces corrosion during the first years of operation, however when the coating is broken down and the $\mathrm{Zn}$ in the coating starts to react with the $\mathrm{HCl}$, or $\mathrm{KCl}$, then localized pitting attack will occur.

\section{Conclusions}

Inspection, collection and analysis of corrosion products from the FGCS in a biomass plant have revealed interesting observations which are specific to the presence of $\mathrm{KCl}$ and $\mathrm{HCl}$ within the flue gas. When firing biomass like straw, corrosion products containing high amounts of alkali, $\mathrm{Cl}$ and $\mathrm{S}$ which originate from biomass are transported through the flue gas system. These components together with high humidity and $\mathrm{HCl}$ in the flue gas have resulted in a fast corrosion rate in some places in the gas-gas preheater such that weathering steel has not had the optimal wet/dry cycles required to achieve a protective oxide. This had the consequence that 316 bolts failed from stress corrosion cracking. 
The use of a $\mathrm{Zn}$ primer has probably led to a reaction in the DeNOx plant between $\mathrm{KCl}$ and $\mathrm{Zn}$ which has contributed to hygroscopic agglomerates of $\mathrm{Zn}-\mathrm{K}-\mathrm{Cl}$ being found in the colder part of the plant after the DeNOx. In other areas, the use of a primer may initially protect components more, however when the primer is partly attacked, the $\mathrm{Zn}$ components are exposed, and can form deliquescent $\mathrm{ZnCl}_{2}$ which absorb water resulting in a localized high $\mathrm{pH}$, and therefore pitting corrosion.

\section{Reference}

1. L. Lindau, B. Goldschmidt "Low temperature corrosion in bark fuelled small boilers" Värmeforsk Report M9-835 (2002 in swedish, 2008 in English)

2. M. Nordling, Corrosion on air preheaters and economisers, Värmeforsk Report M08-815 Nr. 1235. May 2012.

3. J.P. Jensen, L.D. Fenger, N. Henriksen: "Cold-End Corrosion in Biomass and Waste Incineration Plants" Power Plant Chemistry 2001, 2 (8) p. 469-471.

4. T. Herzog, W. Müller, W. Spiegel, J. Brell, D. Molitor, D. Schneider, Corrosion caused by dewpoint and deliquescent salts in the boiler and flue gas cleaning, VGL: KG Thome-

Kozmiensky og M. Beckmann: Energie aus Abfall Band 9 Neuruppin: TK Verlag 2012.p 429-460.

5. M. Montgomery, L.V. Nielsen, M. B. Petersen, Utilization of on-line corrosion monitoring in the flue gas cleaning system, Proceedings NACE International Corrosion Conference 2015, paper 5550 .

6. M. Montgomery, L.V Nielsen, M.B. Petersen, Assessment of corrosion in the flue gas cleaning system using on-line monitoring,VGB Powertech 10, 2015 p.77-83.

7. M. Yamashita, H. Miyuki, Y. Matsuda, H. Nagano, and T. Misawa, The long term growth of the protective rust layer formed on weathering steel by atmospheric corrosion during a quarter of a century, Corr. Sci., Vol 36, 1994, p 283-299

8. I. Diaz, H. Cano, B. Chico, D. de la Fuente and M. Morcillo, Some Clarifications Regarding Literature on Atmospheric Corrosion of Weathering Steels, International Journal of Corrosion, Article 812192, 9 pages

9. W.M Cox, Corrosion Management, Rugby UK, Private Communication 2011.

10. D C Cook, An active coating and new protection technology for weathering steel structures in chloride containing environments, Proceedings NACE International Corrosion Conference 2007 Paper 07360.

11. T.S. Mintz L. Caseres, D.S. Dunn, M. Bayssie, Atmospheric Salt Fog Testing to Evaluate Chloride Induced Stress Corrosion Cracking of Type 304, 304L, and 316 Stainless Steel, Proceedings NACE International Corrosion Conference 2010, Paper 10232.

12. N.D. Fairweather N. Platts, D.R. Tice, Stress corrosion cracking initiation of type 304 stainless steel in atmospheric environments containing chloride: influence of surface condition, relative humidity, temperature and thermal sensitization, Proceedings NACE International Corrosion Conference 2008 Paper 08485.

13. L. Yang, R.T. Pabalan, L. Browning, D.S. Dunn, Corrosion Behavior of Carbon steel and stainless steel materials under salt deposits in simulated dry repository environments, Material Research Society Symposium. Proc. Vol 757, 2003, II4.14.1.

14. Calculated with ThermoCalc database Salt1. 